\title{
Phocomelia, Schinzel type
}

INSERM

\section{Source}

INSERM. (1999). Orphanet: an online rare disease and orphan drug data base.

Phocomelia, Schinzel type. ORPHA:2879

Schinzel phocomelia syndrome, also called limb/pelvis hypoplasia/aplasia syndrome, is characterized by skeletal malformations affecting the ulnae, pelvic bones, fibulae and femora. As the phenotype is similar to that described in the malformation syndrome known as Al-Awadi/Raas-Rothschild syndrome, they are thought to be the same disorder. 